\title{
Size distribution and formation processes of aerosol water-soluble organic carbon during winter and summer in urban Beijing
}

\author{
Xue Ni ${ }^{\mathrm{a}, \mathrm{b}}$, Yuepeng Pan ${ }^{\mathrm{b}}$, Peng Shao ${ }^{\mathrm{c}}$, Shili Tian ${ }^{\mathrm{c}, *}$, Zheng Zong ${ }^{\mathrm{d}}$, Mengna Gu ${ }^{\mathrm{b}}$, Bowen Liu ${ }^{\mathrm{b}}$, \\ Jin Liu $^{\mathrm{b}}$, Jing Cao ${ }^{\mathrm{b}}$, Qian Sun ${ }^{\mathrm{b}}$, Yuesi Wang ${ }^{\mathrm{b}}$, Changsheng Jiang ${ }^{\mathrm{a}}{ }^{* * *}$ \\ ${ }^{a}$ State Cultivation Base of Eco-agriculture for Southwest Mountainous Land, College of Resources and Environment, Southwest University, 400715, Chongqing, China \\ ${ }^{\mathrm{b}}$ State Key Laboratory of Atmospheric Boundary Layer Physics and Atmospheric Chemistry, Institute of Atmospheric Physics, Chinese Academy of Sciences, Beijing \\ 100029, China \\ ${ }^{\mathrm{c}}$ Beijing Center for Physical \& Chemical Analysis, Beijing, 100089, China \\ ${ }^{\mathrm{d}}$ Key Laboratory of Coastal Environmental Processes and Ecological Remediation, Yantai Institute of Coastal Zone Research, Chinese Academy of Sciences, Yantai, \\ 264003, China
}

\section{H I G H L I G H T S}

- Carbonaceous species in both fine and coarse modes decreased from 2013 to 2018.

- The size distribution of WSOC shifted from fine to coarse during haze episodes.

- In summer, coarse mode WSOC was mainly condensed on sea salt.

- In winter, WSOC formation was affected by secondary processes.

\section{A R T I C L E I N F O}

\section{Keywords:}

Water-soluble organic carbon

Haze pollution

Particle size distribution

Secondary processes

Beijing

\section{G R A P H I C A L A B S T R A C T}

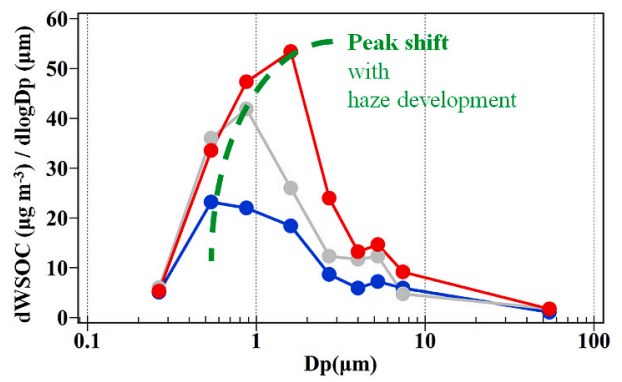

\section{A B S T R A C T}

Size-resolved aerosol organic carbon (OC) and water-soluble OC (WSOC) was determined weekly in urban Beijing between 2013 and 2018. The results showed that in winter, the concentrations of WSOC and OC in fine $(<2.1 \mu \mathrm{m})$ and coarse $(>2.1 \mu \mathrm{m})$ mode were highest in 2013. During the following years, the concentrations of WSOC and OC were lower but an increasing trend was found from 2014 to 2016, which might be due to the increasing precursor concentrations. From summer 2013 to 2018, the concentrations of OC and WSOC in both fine and coarse mode decreased, which might be affected by decreasing emission intensity and photochemical oxidation. To characterize the seasonality of WSOC, two intensive field observations were further performed in winter 2013 and summer 2018. In winter of 2013, WSOC was mainly enriched in $\mathrm{PM}_{1}(<1 \mu \mathrm{m})$ on clean days and lightly polluted days. In addition, the fine mode maximum shifted from $0.43-0.65 \mu \mathrm{m}$ to $1.1-2.1 \mu \mathrm{m}$ with the haze development due to the hygroscopic growth of particles. In summer of 2018, the WSOC was mainly concentrated in $\mathrm{PM}_{1}$, but in a few samples, the maximum size appeared in coarse mode. This difference might due to the different relative humidity and air mass sources. While the formation process of WSOC in winter was affected by photochemical oxidation below $2.1 \mu \mathrm{m}$, in 1.1-2.1 $\mu \mathrm{m}$, it tended to change from photochemical

\footnotetext{
* Corresponding author.

$* *$ Corresponding author.

E-mail addresses: tianshili@mail.iap.ac.cn (S. Tian), jiangcs@126.com (C. Jiang).
} 
oxidation to aqueous-phase oxidation. For the coarse mode WSOC formation in winter, however, it was mainly affected by heterogeneous processes. The findings advanced our understanding of the annual trends, size distribution and formation processes of WSOC, with significant implications for air pollution control in Beijing and surrounding regions.

\section{Introduction}

Water-soluble organic carbon (WSOC) contributes $20 \%-80 \%$ of the total organic carbon (Mader et al., 2004; Zappoli et al., 1999) and significantly affects the hygroscopic growth behavior of aerosols (Zamora et al., 2011). Because of its hydrophilicity, water vapor can condense on aerosol particles as cloud condensation nuclei (CCN) (Novakov and Penner, 1993). In addition, WSOC can promote the absorption of light in the ultraviolet and visible spectral regions, resulting in increased atmospheric light absorption and heating (Dinar et al., 2008). Thus the WSOC closely linked with climate change and air quality. To tackle the problems of both air pollution and regional climate change, it is important to fully understand the size distribution and formation processes of WSOC.

Since the implement of the Air Pollution Prevention and Control Action Plan (denoted as clean air actions) in September 2013, China's anthropogenic emissions had declined sharply. Among these emissions, organic carbon (OC) and black carbon (BC) for $\mathrm{PM}_{2.5}$ had declined by $32 \%$ and 28\% during 2013-2017 (Li et al., 2019). However, the annual trends of WSOC and secondary organic carbon (SOC, which similar with WSOC (Cheng et al., 2010)) remain unclear since the clean air actions especially from a size distribution perspective.

Aerosol WSOC characteristics mostly depend on size distribution. The particle size of WSOC can reflect its mass in the atmosphere, number density, lifetime, atmospheric transmission and light scattering behavior (Duarte et al., 2004). Furthermore, due to the important role of WSOC in the aerosol formation (Chow et al., 2011; Facchini et al., 2000), the WSOC particle size distribution can also provide important information on the haze pollution process.

To date, previous studies on WSOC are mostly limited to the fine particles (Table S1). In $\mathrm{PM}_{2.5}$, WSOC formations were dominated by photochemical oxidation in summer and affected by heterogeneous processes in winter (Du et al., 2014; Pathak et al., 2011; Xiang et al., 2017). In recent years, some studies have investigated the size distribution of WSOC by dividing the sizes into two modes, i.e., fine mode $(<2.5 \mu \mathrm{m})$ and coarse mode $(>2.5 \mu \mathrm{m})$. These studies indicated that WSOC was mainly enriched in the fine mode (Agarwal et al., 2010; Deshmukh et al., 2016) and affected by the photochemical oxidation of volatile organic carbon (VOC) (Deshmukh et al., 2016; Huang et al., 2006). The coarse mode was considered to be mostly affected by soil erosion and other sources, such as pollen and plant fragments (Frka et al., 2018). However, the simple separation of particle as fine-and-coarse mode may miss the detailed characteristics of different particle sizes of WSOC.

In this study, we used the Anderson 9-stage sampler to collect aerosol samples and analysis WSOC in Beijing, where have been subjected to periodic haze pollution in recent years. This study also investigated the annual trends in different sizes of carbonaceous species (WSOC, OC) in winter and summer from 2013 to 2018. Meanwhile, this study selected the winter of 2013 that occurred the most severe haze, and the summer of 2018 that $\mathrm{O}_{\mathrm{x}}\left(\mathrm{NO}_{2}+\mathrm{O}_{3}\right)$ concentrations occurred increase (https ://www.zq12369.com/), to investigate concentrations, size distributions and formation processes of WSOC particle sizes. This dataset may improve our knowledge of the annual trends of WSOC in different sizes and the characteristics of the WSOC particle sizes.

\section{Materials and methods}

\subsection{Sampling site and collection}

The sampling site was on the roof of a building at the Institute of Atmospheric Physics (IAP) $\left(39^{\circ} 58^{\prime} \mathrm{N}, 116^{\circ} 22^{\prime} \mathrm{E}\right)$ (Pan et al., 2016). The building is approximately $8 \mathrm{~m}$ above the ground and is located near the residential area in North Beijing and between the 3rd and 4th ring roads. There was less industrial source of atmospheric pollutants during the study period. The sampling periods were January from 2013 to 2015, August of 2013, 2014, and June and July of 2015.

An Andersen 9-stage sampler (Andersen Series 20-800, USA) was used to collect the particulate matter at a flow rate of $28.3 \mathrm{~L} \mathrm{~min}{ }^{-1}$ (Wang et al., 2016b). The particle size division points were $0.43,0.65$, $1.1,2.1,3.3,4.7,5.8$ and $9 \mu \mathrm{m}$. The sampling membrane in the Andersen sampler is a quartz fiber filter with a diameter of $81 \mathrm{~mm}$. More details about sample collection were described in the Text S1.

To obtain long-term trends, aerosol composition data for the winter 2016 in Beijing was collected from a recent publication (Zhang et al., 2018). The sampling site by (Zhang et al., 2018) was on the roof of a building of Beijing Center For Physical and Chemistry Analysis $\left(39^{\circ} 56^{\prime} \mathrm{N}, 116^{\circ} 18^{\prime} \mathrm{E}\right)$, which is $7.4 \mathrm{~km} \mathrm{SW}$ to the IAP site. In addition, the aerosol data in summer 2016 and winter 2017 were also collected from another study (Lv et al., 2019). The sampling site by (Lv et al., 2019) is on the rooftop of a three-story building on the campus of Beihang University $\left(40^{\circ} 09^{\prime} \mathrm{N}, 116^{\circ} 15^{\prime} \mathrm{E}\right)$, which is $22.5 \mathrm{~km}$ NW to the IAP site. Detailed information for these two sampling sites was described in Text S2.

\subsection{Chemical analysis}

For the size-resolved aerosols that collected in winter 2013 and summer 2018, WSOC, $\mathrm{Na}^{+}, \mathrm{NH}_{4}^{+}, \mathrm{K}^{+}, \mathrm{Mg}^{2+}, \mathrm{Ca}^{2+}, \mathrm{Cl}^{-}, \mathrm{NO}_{3}^{-}$and $\mathrm{SO}_{4}^{2-}$ were determined. A quarter of the quartz filter was cut and extracted in an ultrasonic bath for $30 \mathrm{~min}$ at room temperature using $25 \mathrm{ml}$ of deionized water (Millipore, $18.2 \mathrm{M}$ ). The extraction liquid was filtered using $0.22 \mu \mathrm{m}$ filters and subsequently analyzed in the lab. WSOC concentrations were analyzed by a Multi N/C 3000 analyzer (Analytik Jena AG, Germany) using a nondispersive infrared detector to quantitatively measure the $\mathrm{CO}_{2}$ levels (Pan et al., 2010). The detection limit of total carbon (TC) for this instrument is $0.05 \mathrm{mg} \mathrm{C} \cdot \mathrm{L}^{-1}$. The concentrations of $\mathrm{Na}^{+}, \mathrm{NH}_{4}^{+}, \mathrm{K}^{+}, \mathrm{Mg}^{2+}, \mathrm{Ca}^{2+}, \mathrm{Cl}^{-}, \mathrm{NO}_{3}^{-}$and $\mathrm{SO}_{4}^{2-}$ were analyzed by an ion chromatograph (DIONEX, ICS-90, USA) with methods detailed elsewhere. The methods of $\mathrm{O}_{\mathrm{x}}$ measurements were described in Text S3.

Due to the lack of WSOC data from 2014 to 2017, this study used SOC to replace WSOC considering that the concentrations of SOC were comparable to WSOC (Cheng et al., 2010). The SOC calculation method is described in Text S4. In winter 2014 to 2015 and summer 2013 to 2015, a thermal/optical carbon aerosol analyzer (DRI Model, 2001A, Desert Research Institute, USA) was used to examine the OC and elemental carbon (EC) loaded on the samples. The analysis methods for the carbonaceous species have been reported in previous study (Tian et al., 2014). Same analysis methods were employed by (Lv et al., 2019; Zhang et al., 2018) to obtain the OC and EC data in winter 2016 to 2017 and summer 2016.

\subsection{Backward trajectory analysis}

Hybrid Single-Particle Lagrangian Trajectory (HYSPLIT) software 
was used to simulate the backward trajectory of the air mass during sampling to identify the possible path and source of WSOC. The Global Data Assimilation System (GDAS) meteorological data released by the National Oceanic and Atmospheric Administration (NOAA) were used for backward trajectory analysis. In winter, the temperature was low, and the meteorological conditions were stagnant, which was not conducive to the vertical convolution of the air mass. Therefore, the back trajectories were calculated up to $100 \mathrm{~m}$ above ground level (AGL) for $48 \mathrm{~h}$ for each of the samples and were displayed using Google Earth (Fig. S2). During summer, the back trajectories were calculated up to $500 \mathrm{~m} \mathrm{AGL}$ for $48 \mathrm{~h}$ and analyzed by cluster calculation (Fig. S3). This height was used because pollutants can be well mixed at this altitude (Shen et al., 2019). During precipitation events in summer, the back trajectories were calculated up to $500 \mathrm{~m}$ AGL every $6 \mathrm{~h}$ for a total of $48 \mathrm{~h}$ (Fig. 6).

\subsection{Definition of fine and coarse mode in this study}

Because the Andersen sampler that used in this study does not have cut-off sizes of 2.5 and $10 \mu \mathrm{m}$, fine and coarse mode particles were defined as particles with sizes $<2.1$ and 2.1-9.0 $\mu \mathrm{m}$, respectively. There was a significant linear correlation between $\mathrm{PM}_{2.1}$ and $\mathrm{PM}_{2.5}(p<0.05)$, and between $\mathrm{PM}_{9}$ and $\mathrm{PM}_{10}(p<0.05)$ (Tian et al., 2014).
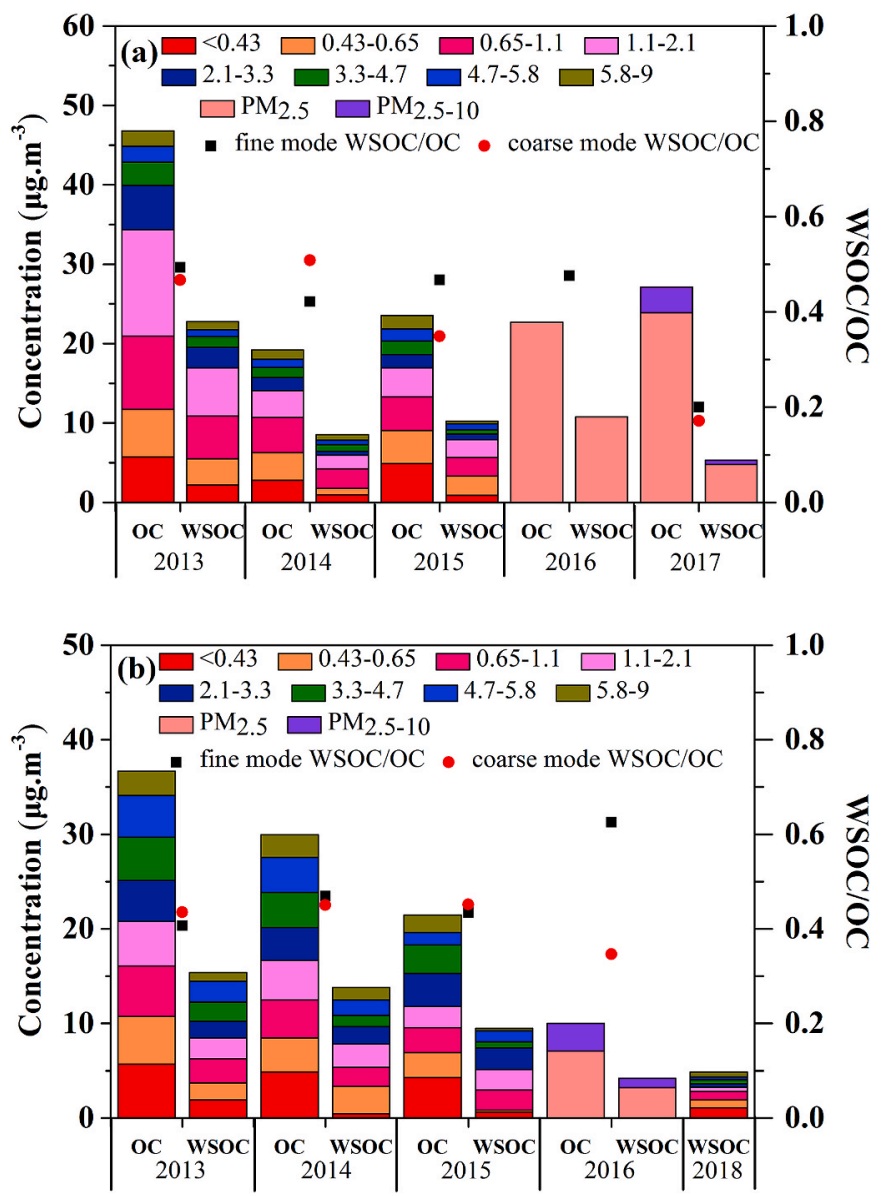

Fig. 1. Annual trends of carbonaceous species (WSOC, OC) in (a) winter from 2013 to 2017 and (b) summer from 2013 to 2018. Data from 2016 to 2017 were from other researches (Lv et al., 2019; Zhang et al., 2018).

\section{Results and discussion}

\subsection{Annual trends of carbonaceous species (WSOC, OC)}

3.1.1. Carbonaceous species (WSOC, OC) in winter from 2013 to 2017 As shown in Fig. 1a, for $\mathrm{PM}_{9}\left(\mathrm{PM}_{10}\right)$, the average concentrations of OC and WSOC in winter from 2013 to 2017 varied from 19.2 to $46.8 \mu \mathrm{g}$ $\mathrm{m}^{-3}$ and from 5.3 to $22.8 \mu \mathrm{g} \mathrm{m}^{-3}$, respectively, and for $\mathrm{PM}_{2.1}\left(\mathrm{PM}_{2.5}\right)$, they ranged from 14.1 to $34.4 \mu \mathrm{g} \mathrm{m}^{-3}$ and $4.8-17.0 \mu \mathrm{g} \mathrm{m}^{-3}$, respectively. The concentrations of OC and WSOC in 2013 were much higher than those in other years because the most severe haze occurred in this year (Ferreri et al., 2018). It was noted that OC increased from 2014 to 2017 and WSOC increased from 2014 to 2016. From 2012 to 2016, the emission of VOCs, which are the precursors of OC and WSOC, was increased (http://meicmodel.org/cloud/). However, $\mathrm{O}_{\mathrm{x}}\left(\mathrm{NO}_{2}+\mathrm{O}_{3}\right)$ and $\mathrm{RH}$, which benefit the formation of WSOC through photochemical oxidation and heterogeneous processes, did not significantly change from 2014 to 2016 (https://www.zq12369.com/). Therefore, formation mechanism might not be the main factor affecting the WSOC and OC trend, and the winter WSOC and OC might mainly be affected by the changes of precursors.

In the fine mode $\left(\mathrm{PM}_{2.1}\right.$ and $\left.\mathrm{PM}_{2.5}\right)$, the concentration of $\mathrm{OC}$ in 2013 was 1.4-2.4 times that in other years, while the concentration of WSOC was 1.6-3.5 times that in other years. In the coarse mode $\left(\mathrm{PM}_{2.1-9}\right.$ and $\mathrm{PM}_{2.5-10}$ ), the concentration of OC in 2013 was 1.9-3.9 times that in other years, while the concentration of WSOC was 2.2-10.6 times that in other years. These results indicated that the decreases in WSOC were greater than those in OC in both the fine and coarse modes. In addition, in the coarse mode, the decreases in WSOC and OC were greater than those in the fine mode.

As secondary organic aerosols account for a large proportion of WSOC, the WSOC/OC ratio can be used to infer the extent of secondary formation and/or aging of aerosols (Ram et al., 2012). For the fine mode, the ratio of WSOC/OC was stable in winter 2013 to 2016. In 2017, the ratio of WSOC/OC significantly declined, indicating that the secondary formation of aerosols was well controlled in winter of this year. WSOC/OC for fine particles exhibited the highest value in 2013 among these years, which was probably attributed to the enhanced SOC production during severe haze days in winter 2013 (Cheng et al., 2013; Zhou et al., 2014). The severe SOC pollution during the haze episodes in winter 2013 was also evidenced by the high OC/EC ratio, which was 9.1. For the coarse mode, the highest WSOC/OC ratio occurred in the winter of 2014. High RH and coarse particles can make WSOC distribute to the coarse mode (Deshmukh et al., 2016; Tian et al., 2014). However, RH during this time was not the highest in these years, indicating that coarse particles might affect the WSOC/OC ratio in this mode during this time.

3.1.2. Carbonaceous species (WSOC, OC) in summer from 2013 to 2018 As shown in Fig. 1b, the concentration of OC decreased in summer from 2013 to 2016, while the concentration of WSOC decreased from 2013 to 2016 but increased in 2018. For $\mathrm{PM}_{9}\left(\mathrm{PM}_{10}\right)$, the average concentrations of OC and WSOC in summer from 2013 to 2018 varied from 10.0 to $36.7 \mu \mathrm{g} \mathrm{m}^{-3}$ and from 4.2 to $15.4 \mu \mathrm{g} \mathrm{m}^{-3}$; for $\mathrm{PM}_{2.1}\left(\mathrm{PM}_{2.5}\right)$, they ranged from 7.1 to $20.8 \mu \mathrm{g} \mathrm{m}^{-3}$ and from 3.3 to $8.5 \mu \mathrm{g} \mathrm{m}^{-3}$. The annual trend of OC concentrations from 2013 to 2016 might be due to the OC emission, which also decreased from 2008 to 2016 (http://meicmodel. org/cloud/). In addition, $\mathrm{O}_{\mathrm{x}}\left(\mathrm{NO}_{2}+\mathrm{O}_{3}\right)$, which benefit the formation of WSOC through photochemical oxidation, decreased from 2014 to 2017 (http://meicmodel.org/cloud/). However, the VOCs trends from 2008 to 2016 were inconsistent with the OC and WSOC trends in summer. This suggesting that the summer OC and WSOC were mainly affected by the emission intensity and photochemical oxidation.

Similar to winter, in the fine and coarse modes, the highest concentrations of OC and WSOC also occurred in summer 2013, while in the coarse mode, WSOC concentrations in summer 2018 were higher compared with summer 2016. This indicated that the air clean actions 
reduced more WSOC in the fine mode than coarse mode.

Due to the lack of OC and EC data in summer 2018, this study only calculated the WSOC/OC ratio in summer 2013 to 2016. In the fine mode, the WSOC/OC ratio in summer 2013 to 2015 was stable, while in summer 2016, it was far higher than in the other years, indicating that in the fine mode, the secondary formation increased in summer 2016. For the coarse mode, the WSOC/OC ratio was stable in summer 2013 to 2015 but decreased in summer 2016. The relative humidity (RH) in summer 2016 was not higher than that in the other years, suggesting that coarse particles might affect the WSOC/OC ratio in this mode.

\subsection{Seasonal characteristics of WSOC}

To investigate the seasonal features of WSOC, this section compared the WSOC characteristics with the dataset obtained in winter 2013 and summer 2018. The reasons why these two campaigns were selected are described in Text S5.

\subsubsection{WSOC concentrations in winter 2013}

As shown in Fig. 2, distinct temporal variations were found in the size-resolved WSOC concentrations during winter. To investigate the variation in WSOC with pollution level, the degree of pollution was divided into several grades. According to the Technical Regulation on Ambient Air Quality Index (HJ633-2012), the pollution level was divided into three grades: clean days $\left(\mathrm{CL}, \mathrm{PM}_{2.5}<75 \mu \mathrm{g} \mathrm{m}^{-3}\right.$ ), lightly polluted days (LP, $75 \mu \mathrm{g} \mathrm{m}^{-3}<\mathrm{PM}_{2.5}<150 \mu \mathrm{g} \mathrm{m}^{-3}$ ) and heavily polluted days (HP, $\mathrm{PM}_{2.5}>150 \mu \mathrm{g} \mathrm{m}^{-3}$ ).

As shown in Fig. S1, the average WSOC concentrations on CL, LP and HP days were $10.4,17.6$ and $33.3 \mu \mathrm{g} \mathrm{m}^{-3}$, respectively. The high WSOC concentrations during LP and HP days were attributed to low winds and high RH (Fig. 2). Particularly, high RH conditions could enhance the
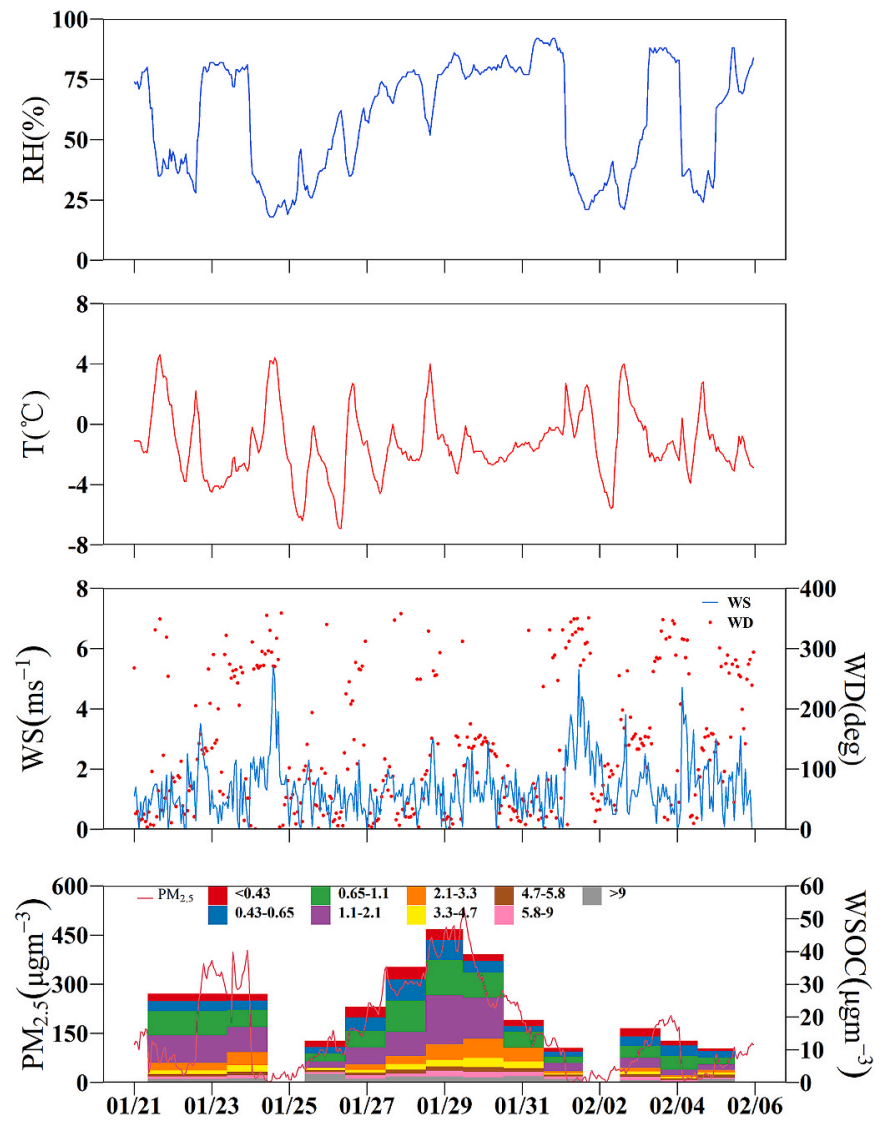

Fig. 2. Temporal variations in meteorological parameters, $\mathrm{PM}_{2.5}$ concentrations and WSOC concentrations in each particle size in winter 2013. formation of secondary organic carbon through aqueous-phase oxidations of VOC (Section 3.3), resulting in an increase in the WSOC concentrations. These meteorological conditions could accelerate the accumulation of organic carbon aerosols through VOC processes (Park and Yu, 2019).

In addition to the meteorological conditions, regional air mass transport also affected the WSOC concentration. During CL days, the dominant air mass was from the northwest (Fig. S2), which passed through Inner Mongolia and the northern part of Hebei Province. This air mass is associated with clean dry air and few airborne pollutants, thus providing a clean atmosphere in Beijing (Xin et al., 2012). During LP and HP days, westerly winds and southerly winds were dominant (Fig. S2). The predominant western air mass trajectory passed through the northwestern part of Shanxi and the western part of Hebei. The southern air mass trajectory traversed Shijiazhuang, Jinan and Baoding. The trajectories from the west and south were characterized by more airborne pollutants since these air masses traversed the highly industrialized areas of China, promoting the occurrence of haze events.

\subsubsection{Size distributions of WSOC in winter 2013}

The size distributions of WSOC on HP, LP and CL days in winter are shown in Fig. 3a. On LP days and CL days, WSOC was mainly enriched in $\mathrm{PM}_{1}$. When the pollution was aggravated (January 26 to 29), the fine mode maximum shifted from $0.43-0.65 \mu \mathrm{m}$ to $1.1-2.1 \mu \mathrm{m}$. The reason for this shift might be the formation of secondary inorganic aerosols, which enhanced the ability of the particles to uptake water (Wang et al., 2018). Secondary inorganic aerosol (SIA), OC and EC are important factors in calculating the hygroscopic parameter $\kappa$ (Cai et al., 2018), and positive feedback exists between the SIA formation process and aerosol hygroscopicity (Wang et al., 2018). To further investigate the
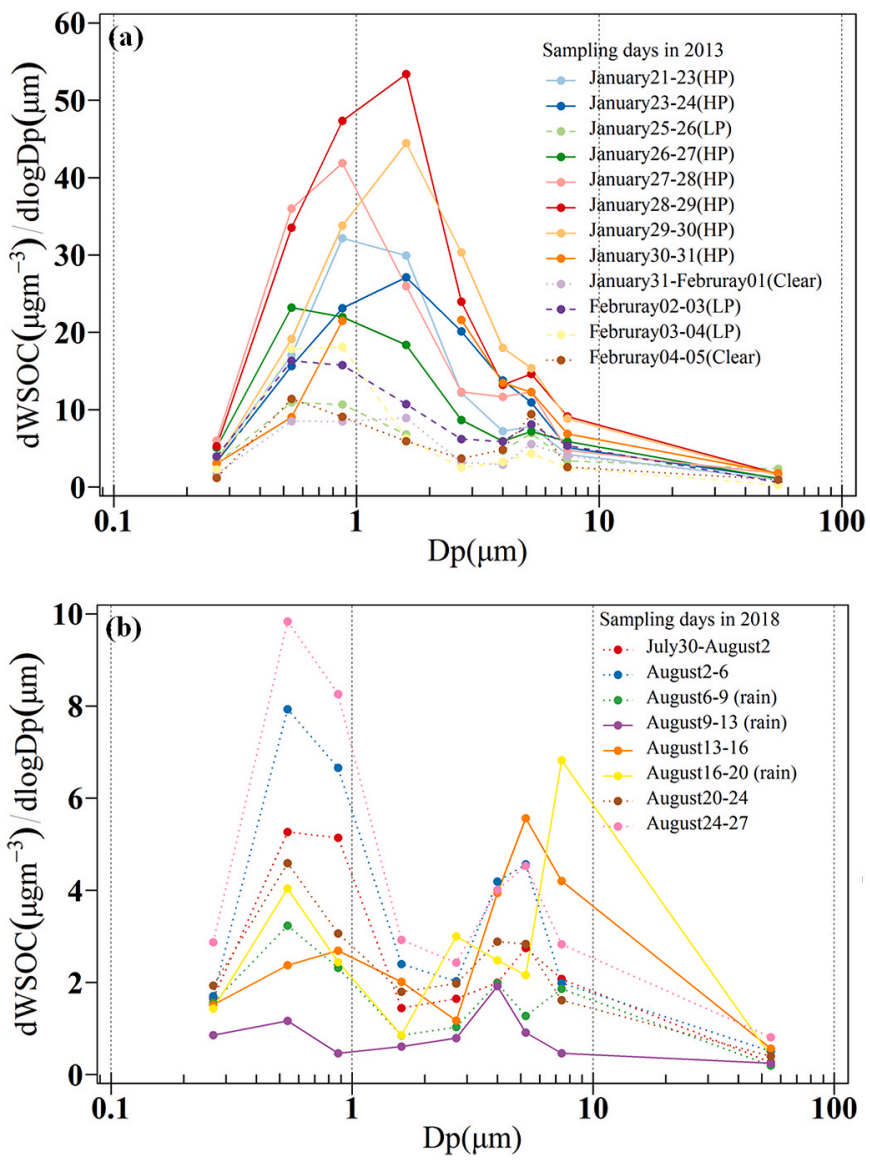

Fig. 3. Size distribution of aerosol WSOC during (a) winter 2013 and (b) summer 2018. 
mechanism of the particle size shift, we selected SIA/(SIA + OC + EC) to characterize the hygroscopicity of the particles (Cai et al., 2018) and RH to characterize the pollution levels.

Fig. 4a shows the correlation of RH with SIA/(SIA + OC + EC) for particle sizes of $0.43-0.65,0.65-1.1$ and $1.1-2.1 \mu \mathrm{m}$. There was a significant positive correlation between $\mathrm{RH}$ and SIA/(SIA + OC + EC) at particle sizes of $0.65-1.1$ and $1.1-2.1 \mu \mathrm{m}$, indicating that the hygroscopicity of these two particle sizes increased during the evolution of haze. However, the existence of EC can reduce the hygroscopicity of a particle because it is the main hydrophobic component in aerosols (Wang et al., 2018). As shown in Fig. 4b, a significant negative correlation between RH and EC/(SIA + OC + EC) was exhibited in the 1.1-2.1 $\mu \mathrm{m}$ range, but there was no significant correlation in the $0.65-1.1 \mu \mathrm{m}$ range. The results shown above suggested that an increase in SIA and a decrease in EC both shifted the size distributions of WSOC to $1.1-2.1 \mu \mathrm{m}$ during the haze event.

\subsubsection{WSOC concentration in summer 2018}

The temporal variations in the WSOC and $\mathrm{PM}_{2.5}$ concentrations in summer are shown in Fig. 5. The WSOC concentration ranged from 1.9 to $9.2 \mu \mathrm{g} \mathrm{m} \mathrm{m}^{-3}$. However, $\mathrm{PM}_{2.5}$ and WSOC did not show a significant
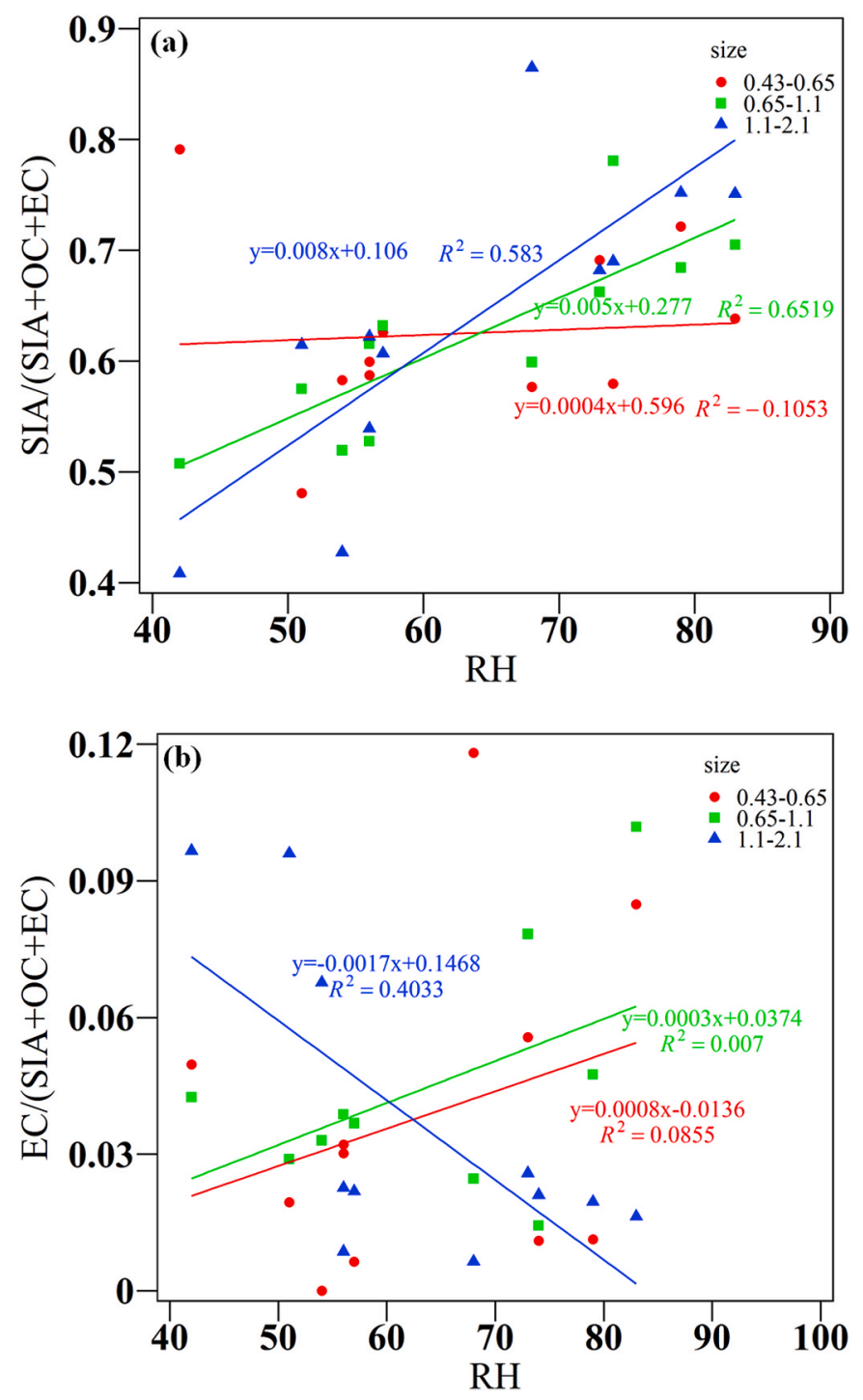

Fig. 4. Correlation between (a) $\mathrm{RH}$ and SIA/(SIA $+\mathrm{OC}+\mathrm{EC}$ ) ratio and (b) EC/ $(\mathrm{SIA}+\mathrm{OC}+\mathrm{EC})$ ratio in the $0.43-0.65,0.65-1.1$ and $1.1-2.1 \mu \mathrm{m}$ size classes in winter 2013.

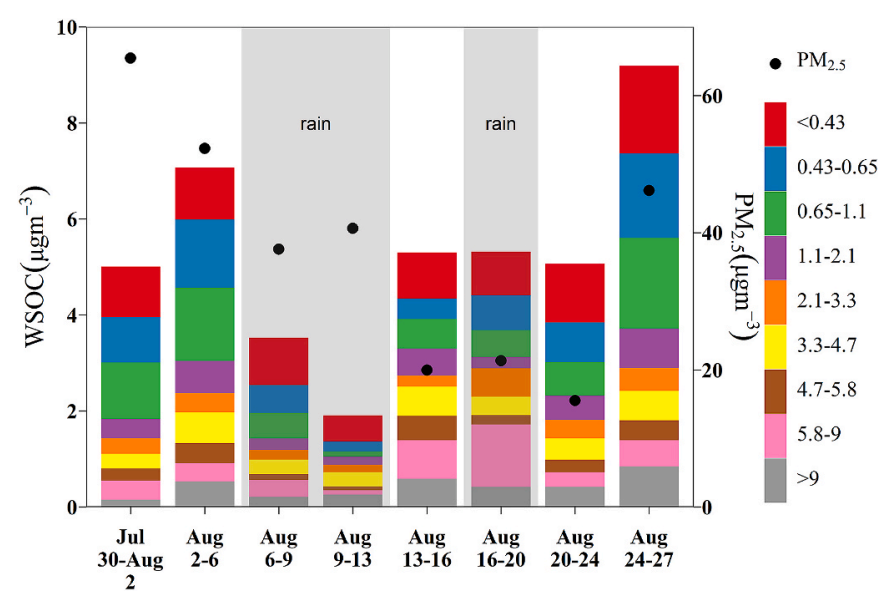

Fig. 5. Water-soluble organic carbon (WSOC) concentration in each particle size and mean $\mathrm{PM}_{2.5}$ value in the summer of 2018 during each sampling period.

correlation in summer. This pattern is different from that in winter 2013. This result might indicate that WSOC was not always follows the temporal variations of $\mathrm{PM}_{2.5}$. In order to investigate the effect of fine and coarse particles on WSOC concentration, we calculated the ratio of coarse mode of WSOC to particle mass in fine and coarse mode. The average $\mathrm{WSOC}_{2.1-9} / \mathrm{PM}_{2.5-10}$ was 0.10 , and the average $\mathrm{WSOC}_{2.1} / \mathrm{PM}_{2.5}$ was 0.11 , this suggesting that the contributions of WSOC to the particle mass in fine and coarse mode were almost the same.

Besides the particle size, air masses transportation also affected WSOC concentration. The backward trajectories in summer were significantly different from that in wintertime (Fig. S3). Most of the trajectories originated from the coastal areas, and a small part originated from northern China where the air is less polluted in summer. Air masses from coastal areas might carry large amounts of coarse particles, such as sea salt (Fig. S3), resulting in a significant positive correlation between WSOC and $\mathrm{PM}_{10}$.

\subsubsection{Size distributions of WSOC in summer 2018}

In summer, the size distributions of WSOC were significantly different from those in winter. As shown in Fig. 3b, the samples that were not affected by precipitation exhibited maxima at $0.43-0.65 \mu \mathrm{m}$. This result was likely due to the strong radiation on sunny days, which promoted photochemical oxidation and enriched the WSOC in the fine mode (Section 3.3). However, during August 9 to 20, the size distributions of WSOC were enriched in the coarse mode. Particle size distribution can be affected by RH (Tian et al., 2014). The RH of August 9 to $20(77 \%)$ was relatively higher than that of the other samples $(73 \%)$. However, it was noted that the RH of August 6 to 9 was also high (88\%). This indicated that the RH was not the only factor that can affect size distributions.

According to previous studies (Agarwal et al., 2010; Timonen et al., 2008), particle transportation can also make the particles enriched in coarse mode. In these studies, coarse mode WSOC was always from marine and dust areas in summer. Therefore, we investigated the backward trajectories during the period of August 6 to 20 (Fig. 6). During August 6 to 9, the backward trajectories did not pass through the marine and dust areas (Fig. 6), resulting in the WSOC remaining enriched in the fine mode. From August 9 to 20, the backward trajectories passed through the Bohai Sea, which could carry sea salt to Beijing, resulting in the WSOC enriched in the coarse mode.

Overall, in summer, the size distributions of WSOC were mainly affected by RH and air mass transportation. The distinct $\mathrm{RH}$ and the effect of air mass transportation caused the difference in the WSOC size distribution. 


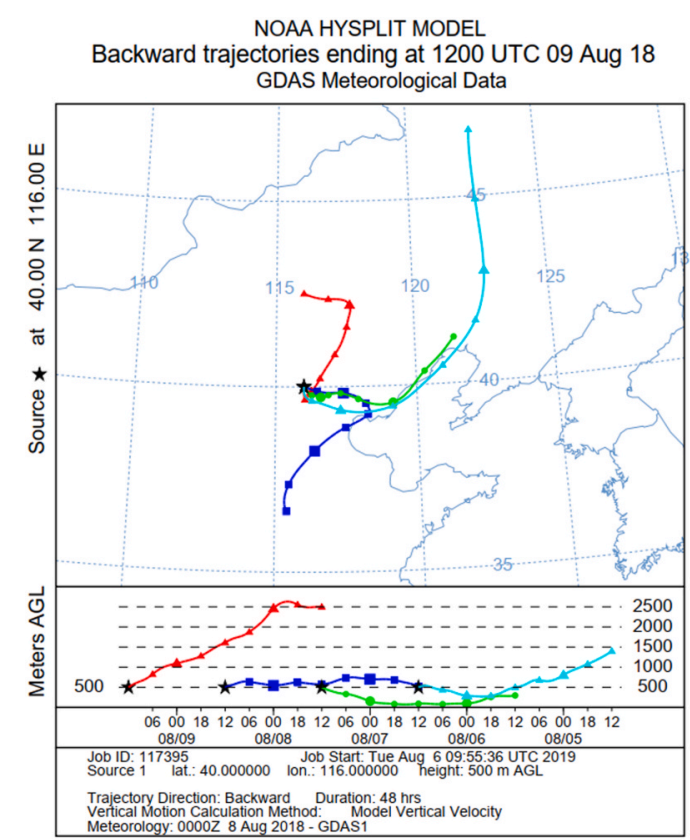

NOAA HYSPLIT MODEL

Backward trajectories ending at 1200 UTC 16 Aug 18 GDAS Meteorological Data

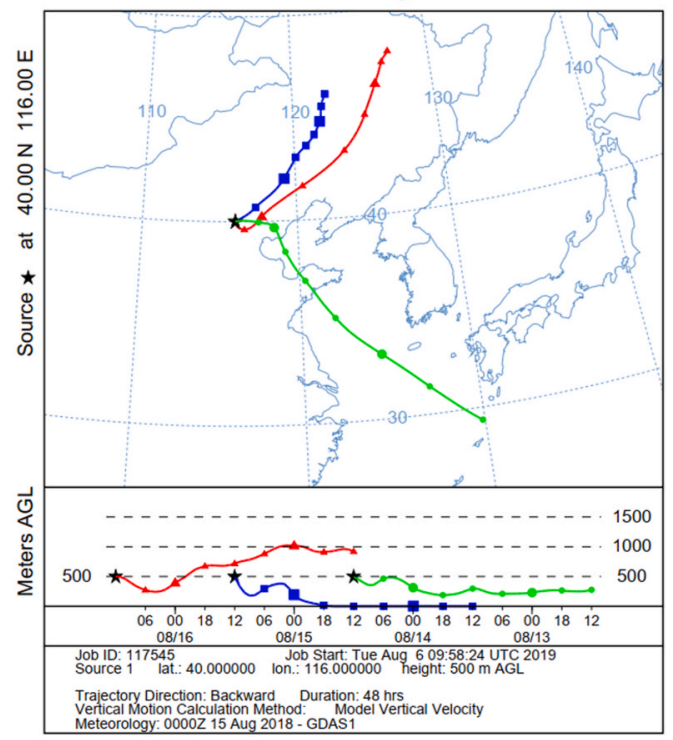

NOAA HYSPLIT MODEL

Backward trajectories ending at 1200 UTC 13 Aug 18 GDAS Meteorological Data

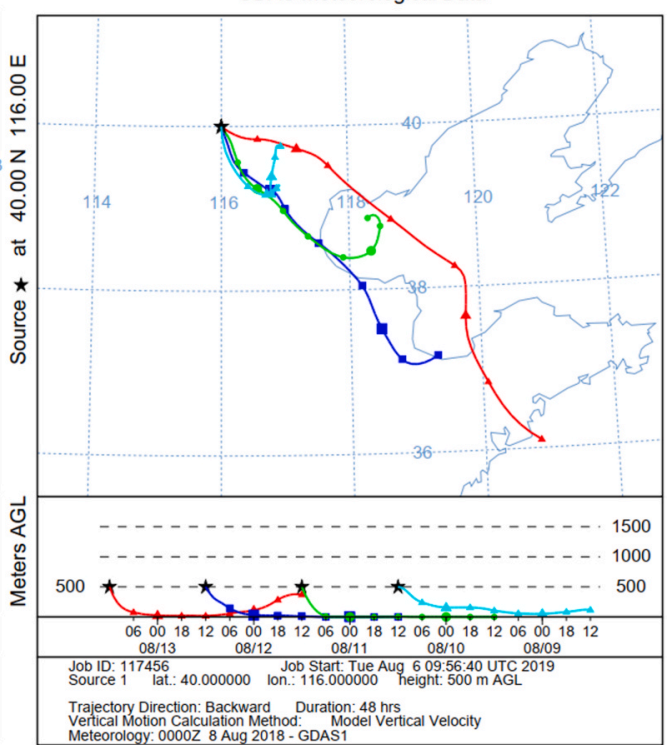

NOAA HYSPLIT MODEL

Backward trajectories ending at 1200 UTC 20 Aug 18 GDAS Meteorological Data

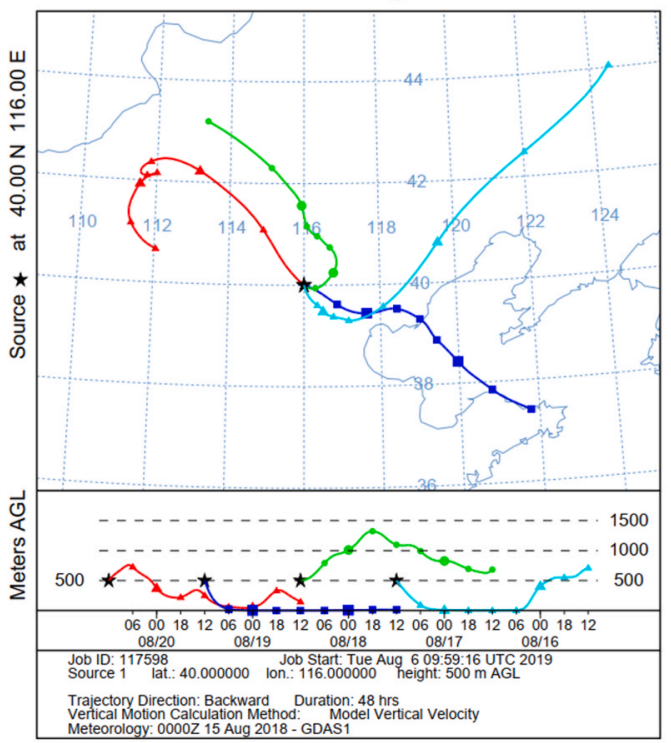

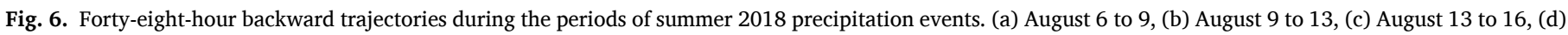
August 16 to 20 .

\subsection{The formation mechanism of WSOC in different particle sizes}

WSOC can be produced from both primary emissions and secondary formation. Table 1 shows the correlation between WSOC and watersoluble ions. During our measurements, the concentrations of WSOC were significantly correlated with $\mathrm{NO}_{3}^{-}, \mathrm{SO}_{4}^{2-}$ and $\mathrm{NH}_{4}^{+}$during both winter and summer (Table 1 ). This finding may indicate that WSOC was subject to a similar formation process as $\mathrm{NO}_{3}^{-}, \mathrm{SO}_{4}^{2-}$ and $\mathrm{NH}_{4}^{+}$through aqueous-phase reactions and homogenous reactions (An et al., 2019). To better understand whether WSOC is related to secondary processes, here we selected $\mathrm{O}_{\mathrm{x}}$ and $\mathrm{RH}$ to characterize photochemical oxidation (Herndon et al., 2008; Notario et al., 2013) and heterogeneous processes (Li et al., 2017; Sun et al., 2013), respectively (Table 2).

During winter haze events, the WSOC concentrations in fine particles (below $2.1 \mu \mathrm{m}$ ) were significantly correlated with $\mathrm{O}_{\mathrm{x}}(p<0.05)$, which indicated that WSOC in the fine mode was affected by photochemical oxidation (Huang et al., 2006, 2014). However, the WSOC concentrations in 1.1-2.1 $\mu \mathrm{m}$ particles were significantly correlated with both $\mathrm{O}_{\mathrm{x}}$ and $\mathrm{RH}$, suggesting that WSOC formation tended to change from photochemical oxidation to aqueous-phase oxidation (Wang et al., 2016a). Evidence can be found in the coarse mode $(>2.1 \mu \mathrm{m})$, where WSOC was significantly correlated with $\mathrm{RH}$, indicating that WSOC in this mode was likely affected by aqueous-phase oxidation (Table 2). WSOC was also correlated with $\mathrm{NO}_{3}^{-}, \mathrm{SO}_{4}^{2-}$ and $\mathrm{NH}_{4}^{+}$in the coarse mode (Table 1). However, $\mathrm{NO}_{3}^{-}$and $\mathrm{SO}_{4}^{2-}$ can associate with base cations in this mode (e.g., $\mathrm{Ca}\left(\mathrm{NO}_{3}\right)_{2}, \mathrm{CaSO}_{4}$ and $\mathrm{NH}_{4} \mathrm{NO}_{3}$ ) (Tao et al., 2019). Therefore, we calculated the coarse mode mass mean aerodynamic diameters (MMADs) of $\mathrm{NO}_{3}^{-}, \mathrm{SO}_{4}^{2-}, \mathrm{NH}_{4}^{+}$and $\mathrm{Ca}^{2+}$. The MMADs of $\mathrm{NO}_{3}^{-}$, $\mathrm{SO}_{4}^{2-}, \mathrm{NH}_{4}^{+}$and $\mathrm{Ca}^{2+}$ in coarse mode were $3.75 \pm 2.15,3.32 \pm 2.20$, $2.23 \pm 3.85$ and $6.20 \pm 1.41 \mu \mathrm{m}$, respectively. It was noted that the MMADs of $\mathrm{NO}_{3}^{-}$and $\mathrm{SO}_{4}^{2-}$ were much smaller than $\mathrm{Ca}^{2+}$, indicating that $\mathrm{NO}_{3}^{-}$and $\mathrm{SO}_{4}^{2-}$ in this mode were likely from hygroscopic growth of 
Table 1

The correlation between WSOC and water-soluble ions in each particle size.

\begin{tabular}{|c|c|c|c|c|c|c|c|c|c|}
\hline & $<0.43$ & $0.43-0.65$ & $0.65-1.1$ & $1.1-2.1$ & $2.1-3.3$ & $3.3-4.7$ & $4.7-5.8$ & $5.8-9$ & $>9$ \\
\hline \multicolumn{10}{|c|}{ Winter } \\
\hline $\mathrm{Na}^{+}$ & 0.275 & $0.606^{*}$ & 0.106 & 0.575 & 0.29 & 0.214 & 0.098 & -0.11 & 0.166 \\
\hline $\mathrm{NH}_{4}^{+}$ & $0.812^{* *}$ & $0.879^{* *}$ & $0.898 * *$ & $0.938^{* * *}$ & $0.866^{* *}$ & $0.902^{* * *}$ & $0.823^{* * *}$ & $0.705^{* *}$ & 0.282 \\
\hline $\mathrm{K}$ & -0.055 & 0.539 & 0.494 & $0.675^{*}$ & $0.751 *$ & $0.825^{* *}$ & 0.624 & 0.091 & 0.529 \\
\hline $\mathrm{Mg}^{2+}$ & -0.384 & -0.259 & -0.113 & -0.038 & -0.124 & 0.145 & 0.059 & 0.274 & $0.839 * *$ \\
\hline $\mathrm{Ca}^{2+}$ & -0.362 & -0.192 & 0.024 & 0.032 & -0.382 & -0.103 & -0.107 & 0.194 & 0.294 \\
\hline $\mathrm{F}^{-}$ & 0.02 & -0.181 & -0.207 & -0.447 & -0.206 & 0 & 0.135 & 0.183 & 0.592 \\
\hline $\mathrm{Cl}$ & 0.498 & $0.668^{*}$ & $0.644 *$ & 0.568 & 0.372 & 0.439 & 0.335 & 0.145 & 0.05 \\
\hline $\mathrm{NO}_{2}^{-}$ & 0.17 & -0.266 & -0.274 & 0.417 & 0.499 & -0.524 & 0.059 & -0.133 & 0.591 \\
\hline $\mathrm{NO}_{3}^{-}$ & $0.830 * *$ & $0.852 * *$ & $0.967^{* *}$ & $0.946^{* * *}$ & $0.925^{* *}$ & $0.922^{* * *}$ & $0.855^{* * *}$ & $0.817^{* *}$ & 0.532 \\
\hline $\mathrm{SO}_{4}^{2-}$ & $0.950^{* *}$ & $0.906^{* *}$ & $0.927^{* *}$ & $0.939^{* * *}$ & $0.967^{* *}$ & $0.945^{* *}$ & $0.873^{* * *}$ & $0.685^{*}$ & 0.334 \\
\hline \multicolumn{10}{|c|}{ Summer } \\
\hline $\mathrm{Na}^{+}$ & -0.043 & -0.219 & -0.174 & 0.008 & -0.542 & 0.334 & 0.474 & -0.291 & -0.161 \\
\hline $\mathrm{NH}_{4}^{+}$ & 0.259 & $0.769^{*}$ & $0.787^{*}$ & 0.262 & -0.018 & 0.106 & 0.393 & -0.123 & -0.184 \\
\hline $\mathrm{K}^{+}$ & -0.03 & 0.465 & 0.674 & -0.142 & -0.061 & 0.474 & 0.183 & 0.206 & 0.035 \\
\hline $\mathrm{Mg}^{2+}$ & 0.202 & 0.466 & 0.591 & 0.038 & -0.093 & -0.38 & 0.336 & -0.128 & -0.309 \\
\hline $\mathrm{Ca}^{2+}$ & 0.3 & 0.239 & 0.595 & 0.398 & 0.692 & 0.288 & $0.725^{*}$ & 0.225 & 0.42 \\
\hline $\mathrm{F}^{-}$ & -0.022 & 0.456 & -0.482 & 0.312 & 0.149 & 0.521 & 0.451 & -0.219 & 0.022 \\
\hline $\mathrm{Cl}^{-}$ & -0.363 & 0.422 & 0.43 & -0.664 & -0.496 & 0.48 & -0.174 & -0.584 & -0.336 \\
\hline $\mathrm{NO}_{2}^{-}$ & 0.051 & -0.042 & -0.148 & 0.318 & -0.027 & 0.324 & 0.535 & 0.399 & -0.154 \\
\hline $\mathrm{NO}_{3}^{-}$ & -0.366 & 0.095 & $0.750^{*}$ & 0.69 & 0.357 & $0.765^{*}$ & 0.662 & -0.024 & 0.378 \\
\hline $\mathrm{SO}_{4}^{2-}$ & 0.294 & $0.709 *$ & $0.864 * *$ & 0.668 & 0.467 & $0.755^{*}$ & $0.870^{* *}$ & 0.453 & 0.627 \\
\hline
\end{tabular}

Table 2

The correlation of each WSOC particle size with $\mathrm{O}_{\mathrm{x}}$ and $\mathrm{RH}$.

\begin{tabular}{|c|c|c|c|c|c|c|c|c|c|}
\hline WSOC & $<0.43$ & $0.43-0.65$ & $0.65-1.1$ & $1.1-2.1$ & $2.1-3.3$ & $3.3-4.7$ & $4.7-5.8$ & $5.8-9$ & $>9$ \\
\hline \multicolumn{10}{|l|}{ Winter } \\
\hline $\mathrm{RH}$ & 0.245 & 0.304 & 0.554 & $0.679 *$ & 0.654 * & $0.664^{*}$ & $0.631 *$ & $0.664 *$ & 0.179 \\
\hline $\begin{array}{l}\mathrm{O}_{\mathrm{x}} \\
\text { Summer }\end{array}$ & $0.857 * *$ & $0.845^{* *}$ & $0.844 * *$ & $0.789 * *$ & 0.556 & 0.525 & $0.597^{*}$ & 0.694 * & 0.376 \\
\hline RH & -0.73 & -0.63 & -0.631 & -0.787 & -0.63 & -0.713 & -0.696 & -0.255 & -0.803 \\
\hline $\mathrm{O}_{\mathrm{x}}$ & 0.249 & 0.6 & 0.653 & 0.319 & 0.211 & 0.083 & 0.118 & -0.239 & 0.025 \\
\hline
\end{tabular}

these in fine mode rather than associated with $\mathrm{Ca}^{2+}$. In addition, the MMADs of $\mathrm{NH}_{4}^{+}$were much smaller than those of $\mathrm{NO}_{3}^{-}$and $\mathrm{SO}_{4}^{2-}$. This suggested that $\mathrm{NH}_{4}^{+}$in the coarse mode was rarely associated with $\mathrm{NO}_{3}^{-}$ and $\mathrm{SO}_{4}^{2-}$, which was mainly from hygroscopic growth of the fine mode (Tao et al., 2019). $\mathrm{NO}_{3}^{-}, \mathrm{SO}_{4}^{2-}$ and $\mathrm{NH}_{4}^{+}$enhanced the hygroscopicity of the particulate matter (Section 3.2), which promoted the heterogeneous oxidation of WSOC in the coarse mode. Furthermore, the WSOC from 4.7 to $9 \mu \mathrm{m}$ was also significantly correlated with $\mathrm{O}_{\mathrm{x}}$. A possible explanation was that part of this WSOC particle size might be from the hygroscopic growth of the fine mode, but this needs further research.

In summer, fine mode WSOC was correlated with $\mathrm{O}_{\mathrm{x}}(0.249<\mathrm{R}<$ $0.653, p>0.05$ ), indicating that WSOC was likely affected by photochemical oxidation in fine particles. In the coarse mode, the correlation coefficients between WSOC and both $\mathrm{O}_{\mathrm{x}}$ and $\mathrm{RH}$ were low, suggesting that WSOC in this mode might not be related to secondary processes (Table 2). Alternatively, coarse mode WSOC in summer may be derived from the emission of high molecular weight organic compounds, mineral dust and sea salt (Mkoma et al., 2013; Wang et al., 2017). In this study, WSOC was correlated with $\mathrm{Ca}^{2+}, \mathrm{NO}_{3}^{-}$and $\mathrm{SO}_{4}^{2-}$. The coexistence of these species in the coarse mode might be associated with mineral dust such as $\mathrm{Ca}\left(\mathrm{NO}_{3}\right)_{2}$ and $\mathrm{CaSO}_{4}$ (Tao et al., 2019). Therefore, the MMADs of $\mathrm{NO}_{3}^{-}, \mathrm{SO}_{4}^{2-}$ and $\mathrm{Ca}^{2+}$ in coarse mode were calculated to determine their existing forms. The MMADs of $\mathrm{SO}_{4}^{2-}$ and $\mathrm{NO}_{3}^{-}$in the coarse mode were slightly lower than those of $\mathrm{Ca}^{2+}\left(\mathrm{Ca}^{2+}: 5.87 \pm 1.82 \mu \mathrm{m} ; \mathrm{SO}_{4}^{2-}: 5.21 \pm\right.$ $1.81 \mu \mathrm{m} ; \mathrm{NO}_{3}^{-}: 6.28 \pm 2.92 \mu \mathrm{m}$ ), indicating that $\mathrm{NO}_{3}^{-}$and $\mathrm{SO}_{4}^{2-}$ were associated with base cations. This result suggested that part of the WSOC in coarse mode was possibly condensed on the surface of $\mathrm{Ca}\left(\mathrm{NO}_{3}\right)_{2}$ and $\mathrm{CaSO}_{4}$ (Park and $\mathrm{Yu}, 2019$ ). Furthermore, the backward trajectories (Fig. S3) revealed that the WSOC in the coarse mode might also coexist with sea salt, although there was no significant correlation between WSOC and $\mathrm{Na}^{+}$(Table 1). From the perspective of size distribution (Fig. S4), WSOC and $\mathrm{Na}^{+}$both peaked at 4.7-5.8 $\mu$ m, indicating that WSOC might be condensed on sea salt.

\section{Conclusions}

In this study, the size distribution and formation processes of WSOC during winter and summer in urban Beijing were investigated between 2013 and 2018. The major results and conclusions are as follows:

(1) Long-term trends. In winter 2013, the WSOC and OC concentrations in both fine and coarse mode were highest than that in 2014-2017 due to the severe haze, and in 2014-2016, WSOC and OC concentrations were lower than 2013 but occurred increase trends, which might be affected by the concentration of precursors. From summer 2013 to 2018, the OC and WSOC concentrations in both fine and coarse mode decreased, which might be mainly affected by the emission intensity and photochemical oxidation.

(2) Size distribution. During heavy polluted days in winter of 2013, the fine mode maximum of WSOC shifted from 0.43-0.65 $\mu \mathrm{m}$ to 1.1-2.1 $\mu \mathrm{m}$, which most likely resulted from the hygroscopic growth of particles. In summer of 2018, WSOC enriched in the coarse mode were due to the different $\mathrm{RH}$ and air mass trajectories.

(3) Formation processes. In winter of 2013, WSOC was mainly affected by photochemical oxidation below $2.1 \mu \mathrm{m}$, and this impact shifted to aqueous-phase oxidation from 1.1 to $2.1 \mu \mathrm{m}$. In 
the coarse mode, WSOC was likely affected by heterogeneous processes. In summer of 2018, fine mode WSOC was affected by photochemical oxidation but not significantly, and coarse mode WSOC was possibly condensed on the surface of $\mathrm{Ca}\left(\mathrm{NO}_{3}\right)_{2}$ and $\mathrm{CaSO}_{4}$ and affected by sea salt.

\section{CRediT authorship contribution statement}

Xue Ni: Formal analysis, Writing - original draft. Yuepeng Pan: Conceptualization, Investigation, Writing - review \& editing. Peng Shao: Writing - review \& editing. Shili Tian: Formal analysis, Writing review \& editing. Zheng Zong: Investigation, Writing - review \& editing. Mengna Gu: Investigation. Bowen Liu: Investigation. Jin Liu: Investigation. Jing Cao: Investigation. Qian Sun: Investigation. Yuesi Wang: Funding acquisition. Changsheng Jiang: Funding acquisition.

\section{Declaration of competing interest}

The authors declare that they have no known competing financial interests or personal relationships that could have appeared to influence the work reported in this paper.

\section{Acknowledgement}

This work was supported by the National Key Research and Development Program of China (Grants: 2017YFC0210103) and National Natural Science Foundation of China (41977186, 41807311).

\section{Appendix A. .Supplementary data}

Supplementary data to this article can be found online at https://doi. org/10.1016/j.brat.2020.103751.

\section{References}

Agarwal, S., Aggarwal, S.G., Okuzawa, K., Kawamura, K., 2010. Size distributions of dicarboxylic acids, ketoacids, $\alpha$-dicarbonyls, sugars, WSOC, OC, EC and inorganic ions in atmospheric particles over Northern Japan: implication for long-range transport of Siberian biomass burning and East Asian polluted aerosols. Atmos. Chem. Phys. 10, 5839-5858.

An, Z., Huang, R.J., Zhang, R., Tie, X., Li, G., Cao, J., Zhou, W., Shi, Z., Han, Y., Gu, Z., Ji, Y., 2019. Severe haze in northern China: a synergy of anthropogenic emissions and atmospheric processes. Proc. Natl. Acad. Sci. U.S.A. 116, 8657-8666.

Cai, M., Tan, H., Chan, C.K., Qin, Y., Xu, H., Li, F., Schurman, M.I., Liu, L., Zhao, J., 2018. The size-resolved cloud condensation nuclei (CCN) activity and its prediction based on aerosol hygroscopicity and composition in the Pearl Delta River (PRD) region during wintertime 2014. Atmos. Chem. Phys. 18, 16419-16437.

Cheng, C., Wang, G., Zhou, B., Meng, J., Li, J., Cao, J., Xiao, S., 2013. Comparison of dicarboxylic acids and related compounds in aerosol samples collected in Xi'an, China during haze and clean periods. Atmos. Environ. 81, 443-449.

Cheng, Y., He, K.B., Duan, F.K., Zheng, M., Ma, Y.L., Tan, J.H., Du, Z.Y., 2010. Improved measurement of carbonaceous aerosol in Beijing, China: intercomparison of sampling and thermal-optical analysis methods. Atmos. Chem. Phys. Discuss. 10, 15671-15712.

Chow, J.C., Bachmann, J.D., Wierman, S.S.G., Mathai, C.V., Malm, W.C., White, W.H., Mueller, P.K., Kumar, N., Watson, J.G., 2011. Visibility: science and regulation. J. Air Waste Manag. Assoc. 52, 973-999.

Deshmukh, D.K., Kawamura, K., Lazaar, M., Kunwar, B., Boreddy, S.K.R., 2016. Dicarboxylic acids, oxoacids, benzoic acid, $\alpha$-dicarbonyls, WSOC, OC, and ions in spring aerosols from Okinawa Island in the western North Pacific Rim: size distributions and formation processes. Atmos. Chem. Phys. 16, 5263-5282.

Dinar, E., Abo Riziq, A., Spindler, C., Erlick, C., Kiss, G., Rudich, Y., 2008. The complex refractive index of atmospheric and model humic-like substances (HULIS) retrieved by a cavity ring down aerosol spectrometer (CRD-AS). Faraday Discuss 137, 279-295.

Du, Z., He, K., Cheng, Y., Duan, F., Ma, Y., Liu, J., Zhang, X., Zheng, M., Weber, R., 2014 A yearlong study of water-soluble organic carbon in Beijing I: sources and its primary vs. secondary nature. Atmos. Environ. 92, 514-521.

Duarte, R.M.B.O., Pio, C.A., Duarte, A.C., 2004. Synchronous scan and excitationemission matrix fluorescence spectroscopy of water-soluble organic compounds in atmospheric aerosols. J. Atmos. Chem. 48, 157-171.

Facchini, M.C., Decesari, S., Mircea, M., Fuzzi, S., Loglio, G., 2000. Surface tension of atmospheric wet aerosol and cloud/fog droplets in relation to their organic carbon content and chemical composition. Atmos. Environ. 34, 4853-4857.
Ferreri, J.M., Peng, R.D., Bell, M.L., Liu, Y., Li, T., Anderson, G.B., 2018. The January 2013 Beijing "Airpocalypse" and its acute effects on emergency and outpatient visits at a Beijing hospital. Air. Qual. Atmos. Health 11, 301-309.

Frka, S., Grgić, I., Turšič, J., Gini, M.I., Eleftheriadis, K., 2018. Seasonal variability of carbon in humic-like matter of ambient size-segregated water soluble organic aerosols from urban background environment. Atmos. Environ. 173, 239-247.

Herndon, S.C., Onasch, T.B., Wood, E.C., Kroll, J.H., Canagaratna, M.R., Jayne, J.T., Zavala, M.A., Knighton, W.B., Mazzoleni, C., Dubey, M.K., Ulbrich, I.M., Jimenez, J. L., Seila, R., de Gouw, J.A., de Foy, B., Fast, J., Molina, L.T., Kolb, C.E., Worsnop, D. R., 2008. Correlation of secondary organic aerosol with odd oxygen in Mexico City. Geophys. Res. Lett. 35.

Huang, R.J., Zhang, Y., Bozzetti, C., Ho, K.F., Cao, J.J., Han, Y., Daellenbach, K.R., Slowik, J.G., Platt, S.M., Canonaco, F., Zotter, P., Wolf, R., Pieber, S.M., Bruns, E.A., Crippa, M., Ciarelli, G., Piazzalunga, A., Schwikowski, M., Abbaszade, G., SchnelleKreis, J., Zimmermann, R., An, Z., Szidat, S., Baltensperger, U., El Haddad, I., Prevot, A.S., 2014. High secondary aerosol contribution to particulate pollution during haze events in China. Nature 514, 218-222.

Huang, X.-F., Yu, J.Z., He, L.-Y., Yuan, Z., 2006. Water-soluble organic carbon and oxalate in aerosols at a coastal urban site in China: size distribution characteristics, sources, and formation mechanisms. J. Geophys. Res. 111.

Li, H., Cheng, J., Zhang, Q., Zheng, B., Zhang, Y., Zheng, G., He, K., 2019. Rapid transition in winter aerosol composition in Beijing from 2014 to 2017: response to clean air actions. Atmos. Chem. Phys. Discuss. 1-26.

Li, H., Ma, Y., Duan, F., He, K., Zhu, L., Huang, T., Kimoto, T., Ma, X., Ma, T., Xu, L., Xu, B., Yang, S., Ye, S., Sun, Z., An, J., Zhang, Z., 2017. Typical winter haze pollution in Zibo, an industrial city in China: characteristics, secondary formation, and regional contribution. Environ. Pollut. 229, 339-349.

Lv, D., Chen, Y., Zhu, T., Li, T., Shen, F., Li, X., Mehmood, T., 2019. The pollution characteristics of $\mathrm{PM}_{10}$ and $\mathrm{PM}_{2.5}$ during summer and winter in Beijing, Suning and Islamabad. Atmos Pollut Res 10, 1159-1164.

Mader, B.T., Yu, J.Z., Xu, J.H., Li, Q.F., Wu, W.S., Flagan, R.C., Seinfeld, J.H., 2004 Molecular composition of the water-soluble fraction of atmospheric carbonaceous aerosols collected during ACE-Asia. J. Geophys. Res. Atmos. 109.

Mkoma, S.L., Kawamura, K., Fu, P.Q., 2013. Contributions of biomass/biofuel burning to organic aerosols and particulate matter in Tanzania, East Africa, based on analyses of ionic species, organic and elemental carbon, levoglucosan and mannosan. Atmos. Chem. Phys. 13, 10325-10338.

Notario, A., Bravo, I., Adame, J.A., Diaz-de-Mera, Y., Aranda, A., Rodriguez, A., Rodriguez, D., 2013. Behaviour and variability of local and regional oxidant levels $\left(\mathrm{O}_{\mathrm{x}}=\mathrm{O}_{3}+\mathrm{NO}_{2}\right)$ measured in a polluted area in central-southern of Iberian Peninsula. Environ. Sci. Pollut. Res. Int. 20, 188-200.

Novakov, T., Penner, J.E., 1993. Large contribution of organic aerosols to cloudcondensation-nuclei concentrations. Nature 365, 823-826.

Pan, Y., Wang, Y., Xin, J., Tang, G., Song, T., Wang, Y., Li, X., Wu, F., 2010. Study on dissolved organic carbon in precipitation in Northern China. Atmos. Environ. 44, 2350-2357.

Pan, Y., Wang, Y., Zhang, J., Liu, Z., Wang, L., Tian, S., Tang, G., Gao, W., Ji, D., Song, T., Wang, Y., 2016. Redefining the importance of nitrate during haze pollution to help optimize an emission control strategy. Atmos. Environ. 141, 197-202.

Park, S., Yu, G.-H., 2019. Absorption properties and size distribution of aerosol particles during the fall season at an urban site of Gwangju, Korea. Environ. Eng. Res. 24, 159-172.

Pathak, R.K., Wang, T., Ho, K.F., Lee, S.C., 2011. Characteristics of summertime $\mathrm{PM}_{2 .}$ organic and elemental carbon in four major Chinese cities: implications of high acidity for water-soluble organic carbon (WSOC). Atmos. Environ. 45, 318-325.

Ram, K., Sarin, M.M., Tripathi, S.N., 2012. Temporal trends in atmospheric $\mathrm{PM}_{2.5}, \mathrm{PM}_{10}$, elemental carbon, organic carbon, water-soluble organic carbon, and optical properties: impact of biomass burning emissions in the Indo-Gangetic Plain. Environ. Sci. Technol. 46, 686-695.

Shen, R., Liu, Z., Chen, X., Wang, Y., Wang, L., Liu, Y., Li, X., 2019. Atmospheric levels, variations, sources and health risk of $\mathrm{PM}_{2.5}$-bound polycyclic aromatic hydrocarbons during winter over the North China Plain. Sci. Total Environ. 655, 581-590.

Sun, Y., Wang, Z., Fu, P., Jiang, Q., Yang, T., Li, J., Ge, X., 2013. The impact of relative humidity on aerosol composition and evolution processes during wintertime in Beijing, China. Atmos. Environ. 77, 927-934.

Tao, J., Zhang, Z., Wu, Y., Zhang, L., Wu, Z., Cheng, P., Li, M., Chen, L., Zhang, R., Cao, J., 2019. Impact of particle number and mass size distributions of major chemical components on particle mass scattering efficiency in urban Guangzhou in southern China. Atmos. Chem. Phys. 19, 8471-8490.

Tian, S., Pan, Y., Liu, Z., Wen, T., Wang, Y., 2014. Size-resolved aerosol chemical analysis of extreme haze pollution events during early 2013 in urban Beijing, China. J. Hazard Mater. 279, 452-460.

Timonen, H., Saarikoski, S., Tolonen-Kivimäki, O., Aurela, M., Saarnio, K., Petäjä, T., Aalto, P.P., Kulmala, M., Pakkanen, T., Hillamo, R., 2008. Size distributions, sources and source areas of water-soluble organic carbon in urban background air. Atmos. Chem. Phys. 8, 5635-5647.

Wang, G., Kawamura, K., Xie, M., Hu, S., Li, J., Zhou, B., Cao, J., An, Z., 2017. Selected water-soluble organic compounds found in size-resolved aerosols collected from urban, mountain and marine atmospheres over East Asia. Tellus Ser. B Chem. Phys, Meteorol. 63, 371-381.

Wang, G., Zhang, R., Gomez, E.M., Yang, L., Zamora, M.L., Hu, M., Lin, Y., Peng, J., Guo, S., Meng, J., Li, J., Cheng, C., Hu, T., Ren, Y., Wang, Y., Gao, J., Cao, J., An, Z., Zhou, W., Li, G., Wang, J., Tian, P., Marrero-Ortiz, W., Secrest, J., Du, Z., Zheng, J., Shang, D., Zeng, L., Shao, M., Wang, W., Huang, Y., Wang, Y., Zhu, Y., Li, Y., Hu, J., Pan, B., Cai, L., Cheng, Y., Ji, Y., Zhang, F., Rosenfeld, D., Liss, P.S., Duce, R.A., 
Kolb, C.E., Molina, M.J., 2016a. Persistent sulfate formation from London Fog to Chinese haze. Proc. Natl. Acad. Sci. U.S.A. 113, 13630-13635.

Wang, J., Pan, Y., Tian, S., Chen, X., Wang, L., Wang, Y., 2016b. Size distributions and health risks of particulate trace elements in rural areas in northeastern China. Atmos. Res. 168, 191-204.

Wang, X., Shen, X.J., Sun, J.Y., Zhang, X.Y., Wang, Y.Q., Zhang, Y.M., Wang, P., Xia, C., Qi, X.F., Zhong, J.T., 2018. Size-resolved hygroscopic behavior of atmospheric aerosols during heavy aerosol pollution episodes in Beijing in December 2016. Atmos. Environ. 194, 188-197.

Xiang, P., Zhou, X., Duan, J., Tan, J., He, K., Yuan, C., Ma, Y., Zhang, Y., 2017. Chemical characteristics of water-soluble organic compounds (WSOC) in $\mathrm{PM}_{2.5}$ in Beijing, China: 2011-2012. Atmos. Res. 183, 104-112.

Xin, J., Wang, Y., Wang, L., Tang, G., Sun, Y., Pan, Y., Ji, D., 2012. Reductions of $\mathrm{PM}_{2.5}$ in Beijing-Tianjin-Hebei urban agglomerations during the 2008 olympic games. Adv. Atmos. Sci. 29, 1330-1342.
Zamora, I.R., Tabazadeh, A., Golden, D.M., Jacobson, M.Z., 2011. Hygroscopic growth of common organic aerosol solutes, including humic substances, as derived from water activity measurements. J. Geophys. Res. Atmos. 116.

Zappoli, S., Andracchio, A., Fuzzi, S., Facchini, M.C., Gelencsér, A., Kiss, G., Krivácsy, Z., Molnár, Á., Mészáros, E., Hansson, H.C., Rosman, K., Zebühr, Y., 1999. Inorganic, organic and macromolecular components of fine aerosol in different areas of Europe in relation to their water solubility. Atmos. Environ. 33, 2733-2743.

Zhang, T., Ma, W., Qi, X., Qu, J., Jia, K., Liu, Y., 2018. Characteristics and sources of organic carbon and element carbon in $\mathrm{PM}_{2.5}$ in the urban areas of Beijing. Environ. Chem. 37, 2758-2766.

Zhou, S., Wang, T., Wang, Z., Li, W., Xu, Z., Wang, X., Yuan, C., Poon, C.N., Louie, P.K.K., Luk, C.W.Y., Wang, W., 2014. Photochemical evolution of organic aerosols observed in urban plumes from Hong Kong and the Pearl River Delta of China. Atmos. Environ. 88, 219-229. 